Research Article

\title{
Effects of Saline Solutions on the Desiccation Cracking and Shrinkage Behavior of Gaomiaozi Bentonite
}

\author{
Long Tan $\mathbb{D}^{1},{ }^{1}$ Penglin Zheng, ${ }^{2}$ and Qingbing Liu $\mathbb{D}^{2}$ \\ ${ }^{1}$ China University of Geosciences, Wuhan 430074, China \\ ${ }^{2}$ Three Gorges Research Center, China University of Geosciences, Wuhan 430074, China \\ Correspondence should be addressed to Qingbing Liu; qingbing@cug.edu.cn
}

Received 13 July 2020; Revised 22 November 2020; Accepted 12 December 2020; Published 24 December 2020

Academic Editor: Payam Shafigh

Copyright (c) 2020 Long Tan et al. This is an open access article distributed under the Creative Commons Attribution License, which permits unrestricted use, distribution, and reproduction in any medium, provided the original work is properly cited.

Bentonite, when used as buffer/backfill material in the deep disposal of high-level radioactive waste (HLW), could undergo desiccation shrinkage or even cracking due to the heat released from HLW, impairing the efficiency of the barrier system. Furthermore, in-service buffer materials are inevitably in contact with the groundwater, which sometimes contain high salt concentrations. The groundwater salinity may modify the properties of bentonite and hence affect the process of desiccation and its performance. To investigate this effect, in this study, a series of temperature-controlled desiccation tests was conducted on compacted specimens of Gaomiaozi (GMZ) bentonite preliminarily saturated with two different saline solutions ( $\mathrm{NaCl}$ and $\mathrm{CaCl}_{2}$ ) at the concentration varying from 0.5 to $2.0 \mathrm{~mol} / \mathrm{L}$. The experimental results indicated that, as the concentration of saline solution increases, the initial saturated water content of bentonite decreases, whereas the residual water content at the completion of the desiccation test increases. The water evaporation rate is reduced for the specimens saturated with a high-concentration saline solution, and $\mathrm{CaCl}_{2}$ has a more significant influence on water evaporation than $\mathrm{NaCl}$. The evolution of cracks on the sample surface during the desiccation process can be divided into four stages: crack growth, maintenance, closure, and stabilization; an increase in the salt concentration effectively inhibits crack development. It was shown that the infiltration of saline solutions alters the microstructure of bentonite by changing the arrangement of clay particles from a dispersed pattern to more aggregate state, which results in a decrease in shrinkage strain and shrinkage anisotropy.

\section{Introduction}

Bentonite has been widely adopted as buffer/backfill material in the deep geological repositories for safe disposal of highlevel radioactive waste (HLW). Bentonite is used as a buffer to isolate the encapsulated canisters that hold HLW and is also applied to backfill the excavations associated with the repository such as deposition tunnels and access tunnels [1]. As the most important component of engineered barrier systems, bentonite can effectively play its role owing to its high swelling potential, low permeability, and excellent radionuclide retardation capacity. In China, the Beishan District of Gansu Province has been chosen as the preferred site for constructing deep repositories for HLW; in situ investigation indicated that the groundwater in the Baishan region contains average total dissolved solids (TDS) of
3-12 g/L (up to $80 \mathrm{~g} / \mathrm{L}$ ) and that the dominant ion types are $\mathrm{Na}^{+}, \mathrm{Ca}^{2+}$, and $\mathrm{Cl}^{-}[2-4]$. When the groundwater seeps through host rock mass into the repository, the concrete and cement-based materials employed for repository construction (e.g., plug structure) could gradually degrade and release large amounts of ions such as $\mathrm{K}^{+}, \mathrm{Na}^{+}$, and $\mathrm{Ca}^{2+}$, which further increases the salinity of the groundwater. The properties of bentonite can be significantly modified when it is subjected to the infiltration of groundwater of high salinity $[5,6]$. On the other hand, the long-term decay of nuclear waste can produce a large quantity of heat, which may induce shrinkage or even desiccation cracking of bentonite and thus damage the barrier performance [7]. Since groundwater salinity can alter the properties of bentonite, it follows that the desiccation and shrinkage behavior of bentonite are also affected by water salinity. This effect, 
however, has not been adequately studied. Obviously, a clear understanding of how the water salinity influences bentonite's desiccation behavior is of importance for assessing the efficiency of the barrier system. This understanding is especially crucial for evaluating the performance of backfill zones as bentonite blocks or pellets used for backfilling are commonly manufactured and installed at a relatively lower density compared with buffer [1, 8, 9]. Backfill with a lower density is more favorable for groundwater inflow and particularly prone to shrinking and cracking when subjected to desiccation.

Extensive research has been conducted on the drying shrinkage behavior of clayey soils. Kowalski [10] investigated the evaporation characteristics of clay and pointed out that the transport of water in a soil mass is driven by the relative difference in water vapor pressures between the soil void and ambient environment. Tang et al. [11] showed that the water evaporation process of saturated thin clay layer consists of three stages: constant-rate, declining-rate, and a final stabilized phase. With regard to volume shrinkage, Tang et al. [12] noted that the shrinkage characteristic curve of clay slurry can be divided into three zones, which are normal, residual, and zero shrinkage. The boundaries of these three zones usually correspond to the air entry point and shrinkage limit, as reported by Cherkov et al. [13]. In addition, for naturally undisturbed soil with an aggregate structure, an initial structural shrinkage stage can appear prior to the normal shrinkage [14-16]. The mechanism behind soil desiccation and shrinkage is recognized as extremely complicated. Suction is normally considered a major factor influencing water evaporation and volume shrinkage, and the drying shrinkage mechanism of clays is also closely related to the diffuse double layer, van der Waals force, and bound water on the clay particle surface [17-19]. It is worth noting that existing research on the impact of pore water chemistry on the performance of the bentonite barrier has mainly focused on the wetting and swelling characteristics [20-22]. With respect to the desiccation behavior, He et al. [23] and Zhang et al. [24] examined the effect of salt concentration on the desiccation cracking, volume shrinkage, and water retention characteristics of GMZ bentonite. Nevertheless, a comprehensive understanding of the effects of salt type and concentration on the drying behavior of GMZ bentonite has not been well established.

The aim of this study is therefore to look into the effect of the saline solution on the behavior of bentonite subjected to desiccation. To this end, a series of drying tests was performed on compacted specimens of GMZ bentonite which were preliminarily immersed in and saturated with two different solutions $\left(\mathrm{NaCl}\right.$ and $\left.\mathrm{CaCl}_{2}\right)$ of varying salt concentrations. The influences of salt type and concentration on the water evaporation, shrinkage deformation, and cracking are presented and analyzed.

\section{Materials and Methods}

2.1. Test Materials and Specimen Preparation. Gaomiaozi bentonite, a preferred buffer material for nuclear waste repositories in China, was used in the experiments and collected from Xinghe County, Inner Mongolia. X-ray Diffraction (XRD) analysis indicated that the test bentonite has a montmorillonite content of $75 \%$, and the nonclay minerals are mainly comprised of quartz and calcite. Table 1 presents the basic properties of the bentonite; the swell index is determined following ASTM D5890 [25].

Prior to sample preparation, a series of light compaction tests were conducted, which indicated an optimal water content of $20 \%$ and a maximum dry density of around $1.4 \mathrm{~g} /$ $\mathrm{cm}^{3}$. The bentonite was first air-dried and then wetted to the optimal water content of $20 \%$ by the addition of distilled water. The wet bentonite was subsequently kept in a sealed container for $24 \mathrm{~h}$ to ensure moisture equalization. Soil specimens were prepared using light compaction equipment; all specimens have a diameter of $50.46 \mathrm{~mm}$ and a height of $10 \mathrm{~mm}$ and are compacted to the maximum dry density of $1.4 \mathrm{~g} / \mathrm{cm}^{3}$. It should be noted that this dry density is lower than that used in the buffer but is comparable to the installed dry density of backfill bentonite $[8,9]$. Two types of saline solutions $\left(\mathrm{NaCl}\right.$ and $\left.\mathrm{CaCl}_{2}\right)$ were separately prepared at three different concentrations $(0.5,1.0$, and $2.0 \mathrm{~mol} / \mathrm{L})$, and the compacted samples were subsequently placed in each saline solution and subjected to vacuum saturation for $48 \mathrm{~h}$. After that, the specimens continue to be immersed in the saline solution for another 7 days to allow full infiltration of the saline solution into the soil. For a comparison purpose, a control specimen was prepared and saturated with distilled water following the same procedure. The details of the prepared specimens are shown in Table 2.

2.2. Test Devices and Methods. Figure 1 shows the setup of the desiccation test, which is comprised of a high-resolution digital camera, drying chamber, electronic balance, and computerized data collection system. The temperature inside the drying chamber can be adjusted in the range of 10 to $90^{\circ} \mathrm{C}$ with an accuracy of $0.1^{\circ} \mathrm{C}$. As reported by Garcia et al. [26] and Guillon et al. [27], the temperature in the geological repository can reach $50 \sim 200^{\circ} \mathrm{C}$ owing to heat transferred from encapsulated nuclear waste and produced by long-term decay of nuclear waste as well as ventilation. Thus, the temperature applied in the desiccation experiment was set to $50^{\circ} \mathrm{C}$ in order to simulate one possible temperature environment within geological repositories. During the test, the specimen was placed on an electronic balance with a precision of $0.01 \mathrm{~g}$, and the soil weight was automatically recorded by the data collection system at a one-minute time interval. As illustrated in Figure 1, a mounted digital camera was used to monitor changes in surface morphology of the specimen during the drying test, and the images were captured at the same time intervals as those used in the collection of soil weight data, ensuring the one-to-one correspondence between two sets of data. During the whole test process, the height and diameter of the specimen were measured with a vernier caliper; for each size, the measurement was conducted at five different positions in the axial or radial direction and the average value was adopted. The test was stopped when the measured weight of specimens remained constant for two hours. 
TABle 1: Basic properties of Gaomiaozi bentonite.

\begin{tabular}{lc}
\hline Indices & Value \\
\hline Specific gravity & 2.69 \\
Liquid limit (\%) & 285 \\
Plastic limit (\%) & 52 \\
Total specific surface area $\left(\mathrm{m}^{2} \cdot \mathrm{g}^{-1}\right)$ & 468.2 \\
Cation exchange capacity $\left(\mathrm{meq}^{-1}\right)$ & 0.78 \\
Swell index $(\mathrm{mL} / 2 \mathrm{~g})$ & 29.5 \\
Shrinkage limit $(\%)$ & 24.0 \\
\hline
\end{tabular}

TABle 2: Designations of specimens prepared with different solution.

\begin{tabular}{lcc}
\hline Designation & Solution used & Concentration of solution $(\mathrm{mol} / \mathrm{L})$ \\
\hline DW & Distilled water & - \\
$0.5 \mathrm{Na}-\mathrm{T}$ & $\mathrm{NaCl}$ & 0.5 \\
$1.0 \mathrm{Na}-\mathrm{T}$ & $\mathrm{NaCl}$ & 1.0 \\
$2.0 \mathrm{Na}-\mathrm{T}$ & $\mathrm{NaCl}$ & 2.0 \\
$0.5 \mathrm{Ca}-\mathrm{T}$ & $\mathrm{CaCl}_{2}$ & 0.5 \\
$1.0 \mathrm{Ca}-\mathrm{T}$ & $\mathrm{CaCl}_{2}$ & 1.0 \\
$2.0 \mathrm{Ca}-\mathrm{T}$ & $\mathrm{CaCl}_{2}$ & 2.0 \\
\hline
\end{tabular}

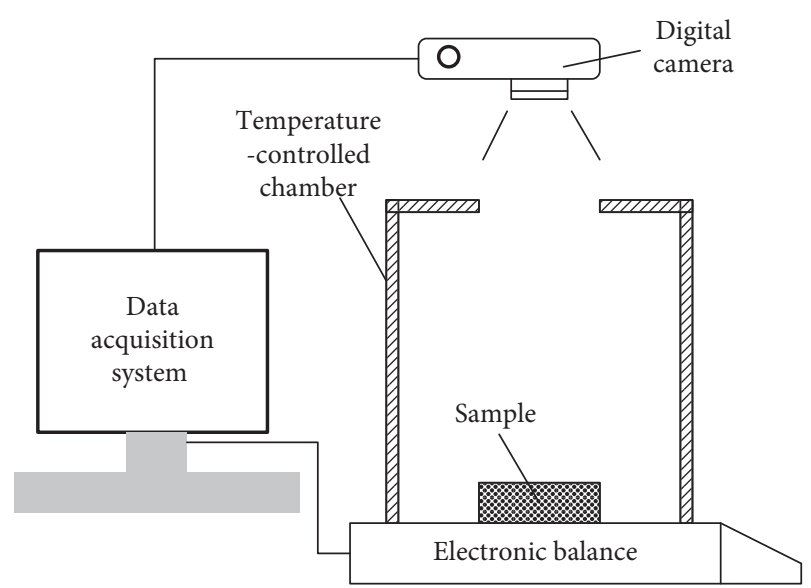

FIgURE 1: The setup of the desiccation test.

2.3. Digital Image Processing. The images of the specimens were digitally processed to quantify crack development during soil shrinkage. Figure 2 shows the flowchart for the digital image processing while Figure 3 illustrates the raw and processed images. The black pixels in the binary image represent cracks, and the surface crack ratio $\delta$ can be computed using the following equation:

$$
\delta=\frac{n}{N}
$$

where $n$ is the number of black pixels and $N$ is the total pixel number. $\delta$ was employed to reflect the degree of shrinkage cracking of the compacted bentonite specimens saturated with different saline solutions of varying concentrations.

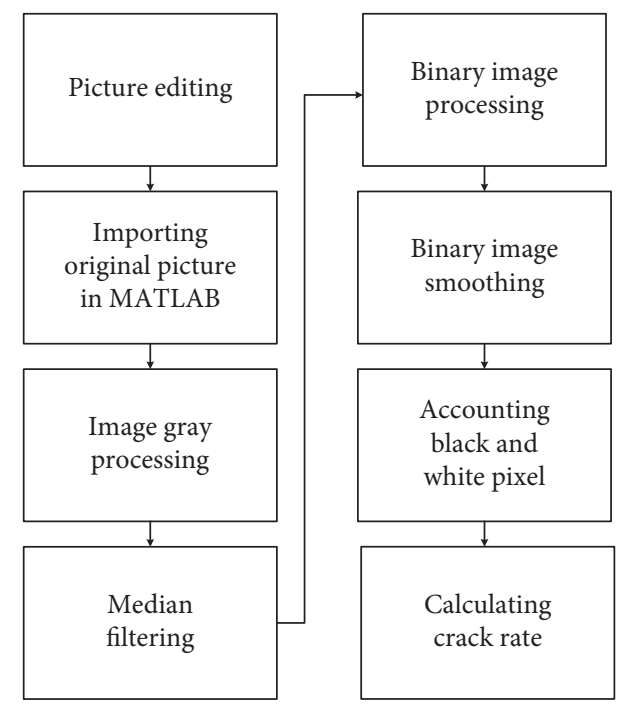

Figure 2: Flowchart for digital image processing.

\section{Results and Discussion}

3.1. Effect of Salinization on the Microstructure of Bentonite. Prior to the desiccation test, a series of scanning electron microscopy (SEM) observations was made on the duplicate bentonite samples, and some typical SEM images are presented in Figure 4. The sample in an as-compacted state, as illustrated in Figure 4(a), demonstrates that there is obvious face-to-face contact between clay particles that are oriented approximately perpendicular to the compaction direction. The preferential orientation of clay particles arising from compaction has also been noted by Hicher et al. [28] and Sato and Suzuki [29]. After being saturated in distilled water, the specimen shows a dispersed structure which is characterized by thin and flaky clay stacks, as indicated in Figure 4(b). It is noted that oriented arrangements are still present for specimen DW, even though the clay particles are fully hydrated and separated from each other. In comparison, for the $2.0 \mathrm{Na}-\mathrm{T}$ specimen, more mineral layers are bonded together to form thicker stacks, some of which are further clustered together into clay aggregates (see Figure $4(\mathrm{c})$ ). After being saturated with $2.0 \mathrm{~mol} / \mathrm{L} \mathrm{CaCl}_{2}$ solution, the bentonite specimen, as shown in Figure 4(d), exhibits an apparent aggregate structure with complete disappearance of flat-shaped stacks of clay platelets, and the aggregated particles are arranged in a disordered manner with the presence of some interaggregate pores. The observed flocculation of clay particles induced by the saline solution is in reasonable agreement with existing studies $[30,31]$. It is of note that the particle aggregation for specimen $2.0 \mathrm{Ca}-\mathrm{T}$ is more significant than that of specimen $2.0 \mathrm{Na}-\mathrm{T}$.

The difference in the microstructures of these three bentonite specimens can be explained in terms of the effect of solution type. When saturated with distilled (deionized) 


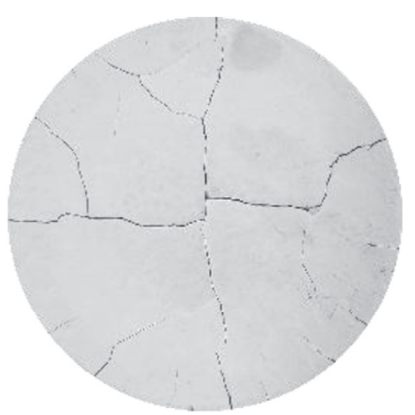

(a)

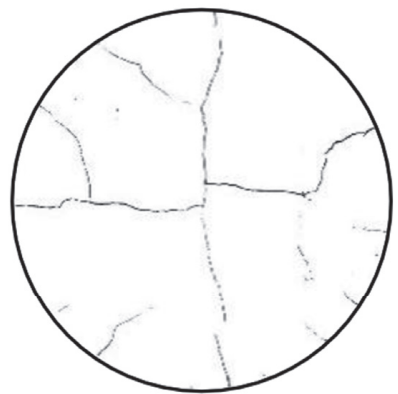

(b)

FIGURE 3: Raw and binary images.

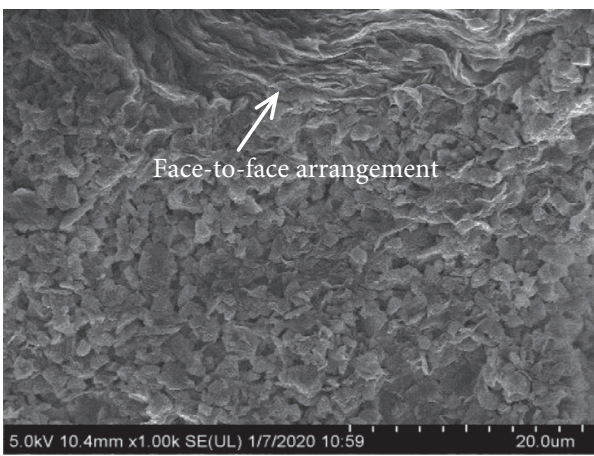

(a)

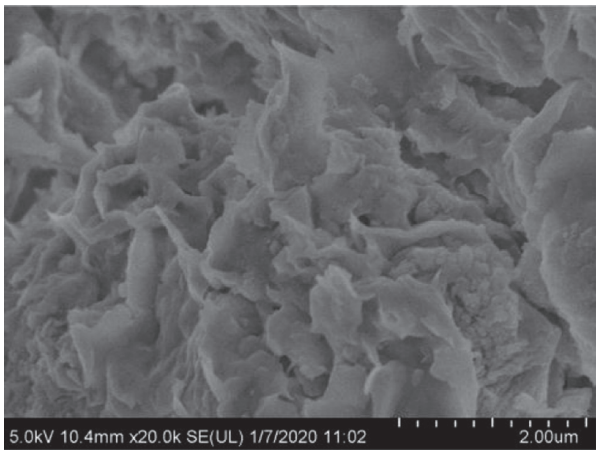

(c)

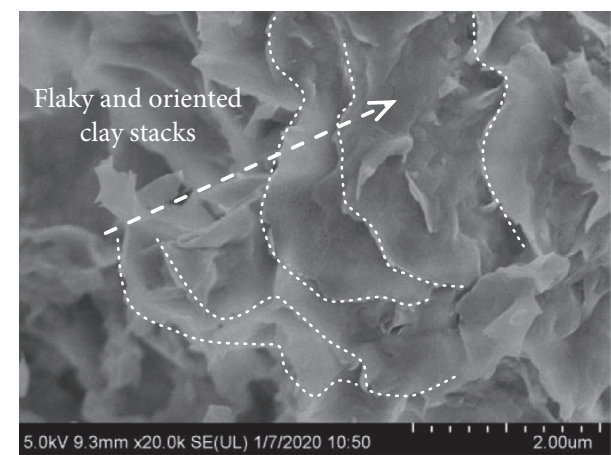

(b)

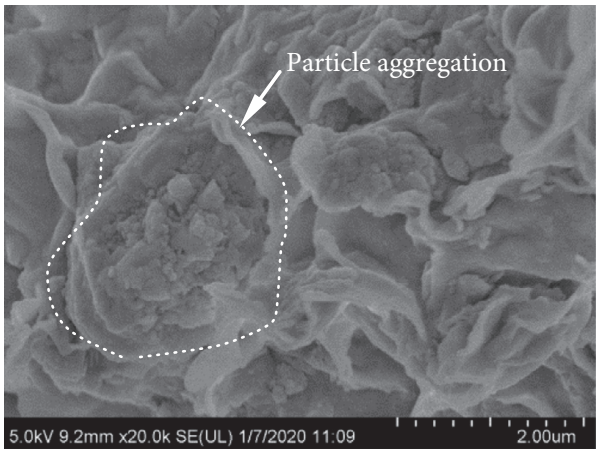

(d)

FiguRE 4: SEM images of bentonite: (a) sample after compaction (×1000); (b) DW $(\times 20000)$; (c) 2.0Na-T (×20000); (d) 2.0Ca-T ( $\times 20000)$.

water, the montmorillonite is fully hydrated with the diffuse double layer well developed, which is accompanied by oriented separation of clay particles along the direction of crystalline (interlayer) expansion. As aforementioned, during this process, the oriented structures of the as-compacted sample are sustained to some extent. When the bentonite is exposed to a saline solution of high concentration, osmotic suction will be induced, and this can act as an internal effective compaction stress to cause particles to come close together; on the other hand, a high cation content provided by the salt solution will screen the double-layer repulsion, resulting in an increase in the attraction between clay platelets $[32,33]$. The combination of these two effects contributes to the aggregation of clay particles. In addition, at a given concentration, compared with $\mathrm{Na}^{+}, \mathrm{Ca}^{2+}$ can exert a higher level of suppression on the electrical double layer because of its larger number of valence electrons; therefore, the specimens saturated with $\mathrm{CaCl}_{2}$ solution show a higher level of particle aggregation and more remarkable aggregate structure. Furthermore, it can be seen that the aggregation effects induced by the salt solution lead to the microstructure changing from oriented clay stacks to a nondirectional distribution of clay aggregates.

3.2. Water Evaporation Characteristics of Bentonite upon Drying. The variation of water content with drying time for different bentonite specimens is shown in Figure 5, where $w$ and $t$ denote water content and elapsed time, respectively. Table 3 presents the initial water content (after saturation) 


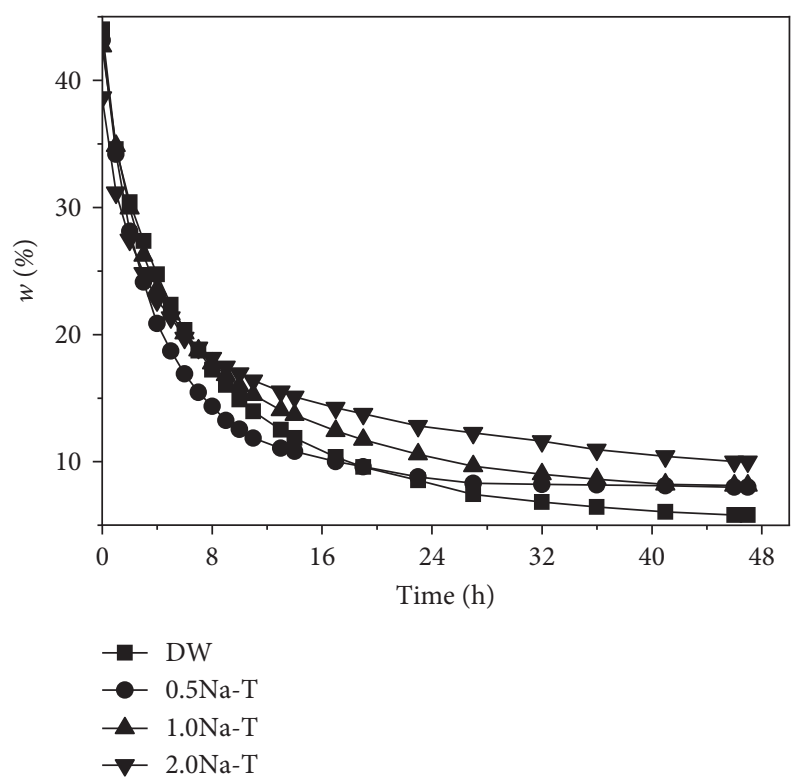

(a)

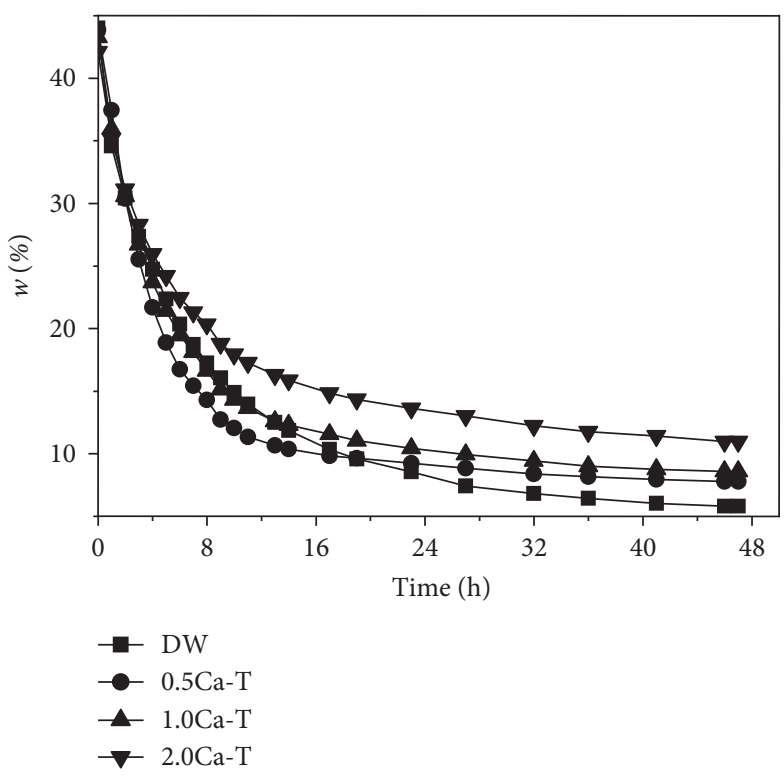

(b)

Figure 5: Variation of water content with elapsed drying time.

TABLE 3: Initial and residual water content of specimens.

\begin{tabular}{lcc}
\hline Designation & $\begin{array}{c}\text { Initial water content } w_{i} \\
(\%)\end{array}$ & $\begin{array}{c}\text { Residual water content } w_{e} \\
(\%)\end{array}$ \\
\hline $\mathrm{DW}$ & $44.00( \pm 0.20)$ & 5.81 \\
$0.5 \mathrm{Na}-\mathrm{T}$ & $43.14( \pm 0.16)$ & 7.99 \\
$1.0 \mathrm{Na}-\mathrm{T}$ & $42.66( \pm 0.23)$ & 8.12 \\
$2.0 \mathrm{Na}-\mathrm{T}$ & $39.28( \pm 0.27)$ & 9.56 \\
$0.5 \mathrm{Ca}-\mathrm{T}$ & $43.86( \pm 0.15)$ & 7.32 \\
$1.0 \mathrm{Ca}-\mathrm{T}$ & $43.28( \pm 0.15)$ & 8.59 \\
$2.0 \mathrm{Ca}-\mathrm{T}$ & $40.65( \pm 0.22)$ & 10.97 \\
\hline
\end{tabular}

and residual water content (at the end of the drying test) of the specimens, and the initial water content $\left(w_{i}\right)$ for all salinized specimens is seen to be lower than that of specimen DW, with a tendency for $w_{i}$ to decrease as the salt concentration increases. The relatively lower $w_{i}$ value is attributed to the osmotic suction induced by the salt solution. When the as-compacted specimens were immersed in distilled water, the dissipation of matric suction will lead to water flow into the soil and a gradual increase in the water content of specimens. However, in the case of saline solution, in addition to soil matric suction, an osmotic suction gradient will occur between the soil pore water and the external solution, which induces the inward diffusion of salts into the specimen and outward osmotic flow of soil water $[34,35]$. Therefore, given that matric suction is the same for all specimens compacted under identical initial conditions, a higher osmotic suction will give rise to more osmotic flow of soil water towards the external solution, thereby accounting for the lower initial water content of the specimens saturated with high-concentration solutions.

As indicated in Figure 5, the general trend for water content to vary with drying time is similar for all specimens; the water content rapidly decreases within the initial 2 hours and then decreases with time at a slowing rate until the residual (constant) water content is finally reached. During the initial drying period, the rapid reduction in water content is due to the loss of free water on the near surface of the sample. As the desiccations proceed, the decreasing rate of water evaporation may arise from three aspects: (1) soil shrinkage accompanied by a decrease in the pore volume and size renders the moisture immigration through the soil pores more difficult; (2) as the water near the soil surface evaporates, the drying front gradually moves forward into the internal zone of the sample [36] and water molecules in the inner part of the soil have to diffuse along a longer pathway to escape from the soil surface; in addition, an increase in soil suction would lead to a decrease in the vapor pressure gradient at the soil-air interface, which is essentially the driver of water evaporation [37]; (3) when the free water is completely removed, the loosely bound water will start to evaporate; however, this type of water is adsorbed on the surface of clay particles at a relatively high energy state and hence requires an even longer time to be removed.

It should be mentioned that the residual water content $\left(w_{e}\right)$ stems from the strongly bound water which can only be removed at a much higher temperature than that used in the present desiccation test. The formation mechanisms for the strongly bound water of montmorillonite are usually considered to involve hydrogen bonding of the polar water molecules with oxygen atoms $(\mathrm{O})$ and hydroxyl radicals $(\mathrm{OH})$ on tetrahedral and octahedral sheets, the thin water film adsorbed on the interlayer surface, and the hydration of countercations (i.e., a certain number of water molecules surround the cation in the form of a salvation shell) [38]. As indicated in Table 3, the salinized specimens have higher residual water content $\left(w_{e}\right)$ than specimen DW and $w_{e}$ increases with the solution concentration; this may be because that the specimens saturated with high-concentration 
saline solution possess more hydrated cations $\left(\mathrm{Na}^{+}\right.$and $\mathrm{Ca}^{2+}$ ), which exist on the soil particle surface and in the pores and, as mentioned above, contribute to the residual water content. In addition, at a given concentration, the specimens treated with $\mathrm{CaCl}_{2}$ generally show a higher $w_{e}$ value than those treated with $\mathrm{NaCl}$, which may arise as the hydration number, defined as the average number of water molecules bound to one cation, is higher for $\mathrm{Ca}^{2+}$ than for $\mathrm{Na}^{+}$[39].

Figure 6 shows the variation of water evaporation rate $(R)$ with water content $(w)$ for the specimens upon drying, where the water evaporation rate is defined as the first derivative of water content with respect to time; that is, $R=d_{w} / d_{t}$. The evaporation rate is seen to reduce almost linearly with the decrease of water content at first and then to decline slowly to zero when the water content falls below approximately $20 \%$. At a given water content, the evaporation rate appears to decrease as the salt concentration increases; this may be caused by the relatively higher osmotic suction of the specimens saturated with the high-concentration solution, as water evaporation is driven by the vapor pressure gradient between the soil pore water and the ambient air and an increase in osmotic suction will induce a decrease in vapor pressure within soil pores resulting in a lower vapor pressure gradient. As shown in Figure 6(c), the specimens salinized with $\mathrm{CaCl}_{2}$ have a lower $R$ value than those treated by $\mathrm{NaCl}$ with the same concentrations; the reason for this, in addition to the higher osmotic suction induced by $\mathrm{CaCl}_{2}$ solution, may lie in the fact that the $\mathrm{Ca}^{2+}$ cation, once adsorbed to the interlayer space of montmorillonite through cation exchange, can lead to a higher electrostatic attraction within the "cation-water moleculeinterlayer surface" system as well as a higher strength of the bonding between the cation and water molecule due to its larger hydration energy and higher valence in comparison with the $\mathrm{Na}^{+}$cation [39].

The soil water evaporation rate is known to be affected by many factors such as the temperature, humidity, soil structure, suction, pore water chemistry, and type of soil water [11]. Figures 6(a) and 6(b) show that, in the initial stage of the desiccation test, the evaporation rate of the specimen DW is lower than those of specimens saturated with a salt solution with a concentration of $0.5 \mathrm{~mol} / \mathrm{L}$ but is higher than those of highly salinized specimens (treated with a $2 \mathrm{~mol} / \mathrm{L}$ solution). This phenomenon may arise from the effects of both soil structure and osmotic suction. For specimen DW, which is highly hydrated with a fully dispersed structure (see Figure 4(b)), the water lost at the beginning of the drying test was initially adsorbed in the micropores between the dispersed clay particles. In contrast, the specimens $0.5 \mathrm{Na}-\mathrm{T}$ or $0.5 \mathrm{Ca}-\mathrm{T}$ may have an aggregate structure with the presence of some interaggregate pores, and the water located within these large interaggregate pores will be evaporated first. It is clear that the adsorptive strength of water retained in micropores is higher than that within the large pores; therefore, the specimen DW shows a lower evaporation rate. However, in terms of the highly salinized specimens, which also contain many interaggregate pores, the very high osmotic suction induced by the salt solution can result in an even more significant reduction in the vapor pressure gradient, and in such case, the effect of osmotic suction would dominate over that of soil structure, thus giving rise to a lower evaporation rate shown by highly salinized specimens. In sum, the initial evaporation rate is controlled by the dominant factor (e.g., soil structure and osmotic suction), which depends on the magnitude of the salt concentration employed.

\subsection{Desiccation Cracking Behavior of Bentonite Specimens.} The images for various specimens at the end of the drying test are presented in Figure 7. Interconnected and wide cracks are evident on the surface of specimen DW whereas the development of cracks for the salinized specimens is less significant. In addition, the extent of the cracking tends to reduce as the concentration of the saline solution increases, and in particular, there are almost no visible macrocracks that can be observed for the specimens saturated with highconcentration $(2 \mathrm{~mol} / \mathrm{L})$ salt solutions.

The images captured for each specimen during the drying process were processed following the procedure shown in Figure 3 and the surface crack ratios, $\delta$, of the specimens at different time points were determined using equation (1). The variations of surface crack ratio $(\delta)$ with water content $(w)$ are shown in Figures 8 and 9, where representative images corresponding to some particular water content are also presented. It can be seen that the evolution of soil cracking upon drying can be divided into four stages, which are crack growth, maintenance, closure, and stabilization. In the stage of crack growth, $\delta$ increases linearly as the water content decreases, and the rate of the increase in $\delta$, as represented by the slope of the red fitting line in the figures, decreases as the concentration of the saline solution increases. In other words, when the amount of soil water loss is the same, a higher solution concentration will lead to a lower $\delta$ value and is, therefore, more effective in inhibiting soil cracking during this stage. After $\delta$ increases to a peak value, the second stage occurs where the surface crack ratio is maintained at a nearly constant value as the water content decreases. As shown in Figures 8 and 9, the duration of the second stage seems to decrease as the concentration of the saline solution increases. With further desiccation, the specimens enter a third stage where the $\delta$ value gradually decreases due to the closing of some developed cracks, and once the water content decreases to a threshold value, the final stabilized phase appears when the $\delta$ value is no longer varying. It is of note that the water content of each specimen at the onset of the crack-stabilized stage is somewhat higher than the residual water content $\left(w_{e}\right)$ provided in Table 3 .

The mechanism of desiccation cracking is recognized to be related to the developed matric suction, which can induce internal tensile stress that acts on the soil particles; the crack initiates when the tensile stress exceeds the soil tensile strength. The growth of cracks proceeds as the suctiondependent tensile stress increases and stops when the soils have sufficient stiffness and tensile strength to resist cracking. Despite this existing understanding, there seems to be no fundamental explanation available for the 


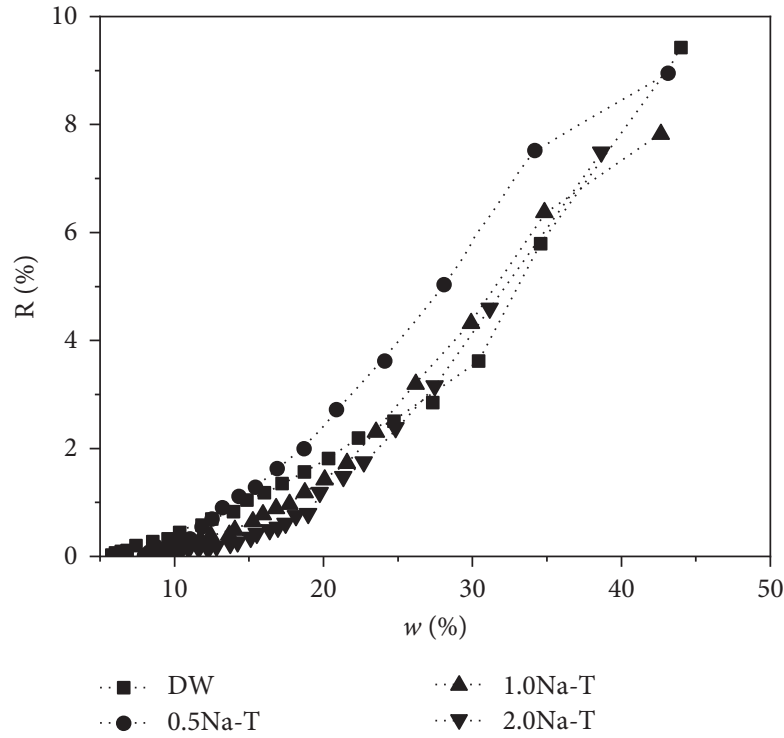

(a)

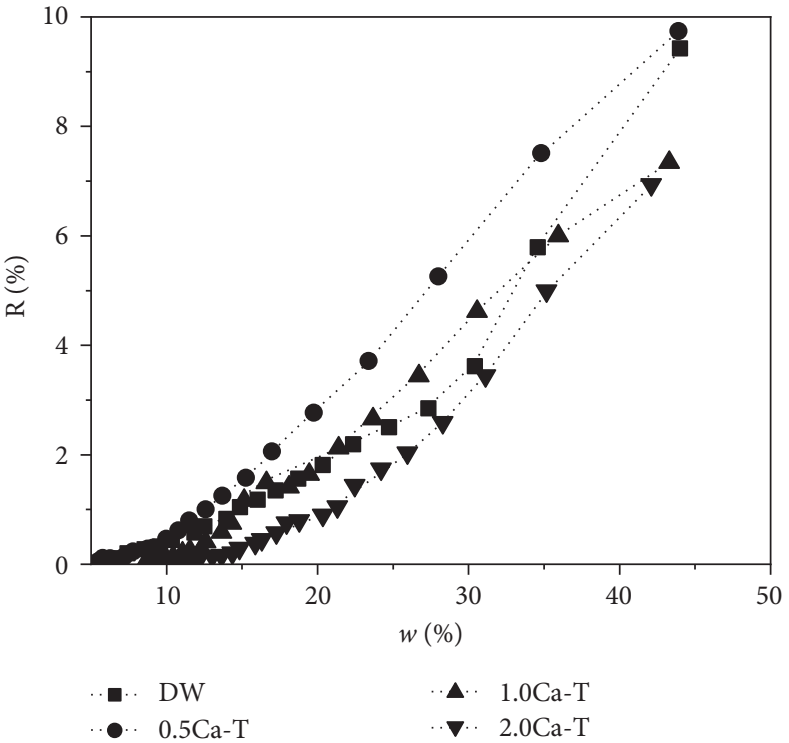

(b)

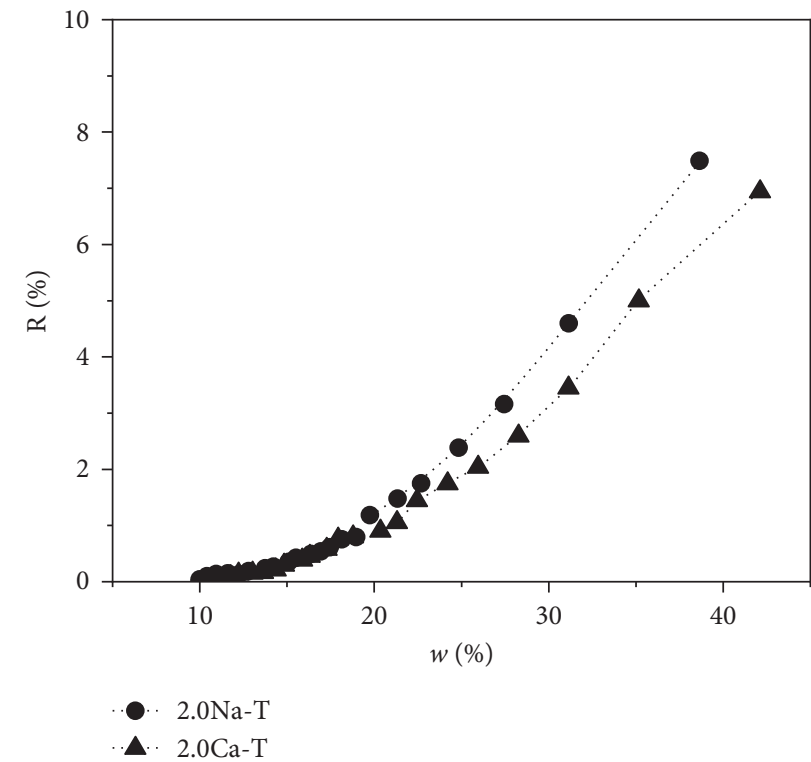

(c)

Figure 6: Variation of evaporation rate with water content.

phenomenon of crack closing that was observed in the present experiments. It is worth mentioning that similar observations have also been made in previous studies, which showed that the cracks tended to close at the dry end of the shrinkage curve $[13,40]$. A possible reason for this phenomenon may lie in the uneven shrinkage undergone by specimens. When subjected to heat, soil water in the vicinity of the outer boundary of the circular specimen evaporates faster than that contained in the central part of the specimen. Accordingly, the shrinkage deformation of the outer part of the specimen is larger than that of the inner part; in other words, the inner part may behave like a "wet core" resisting the shrinkage of the outer part towards the sample center, which induces tensile stress in the circumferential direction.
When this tensile stress exceeds the tensile strength, cracks occur along the radial direction. In the later stage of the drying test, the outer part of the sample tends to cease shrinking as its water content decreases to a constant value; however, as the drying front gradually moves towards the sample center, the shrinkage of the inner part proceeds. Given that the whole sample, despite cracking, can still be considered as a continuum medium, the outer soil parts around the cracks will move towards the sample center (similar to rigid motion) in response to the shrinkage of the soil inner part, thereby compressing the crack width and leading to gradual closing of cracks.

The associated parameters of cracking for different specimens are provided in Table 4, which indicates that as 


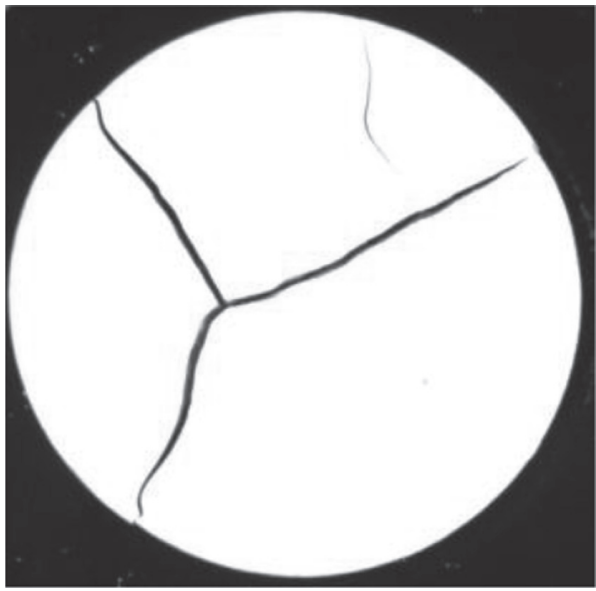

(a)

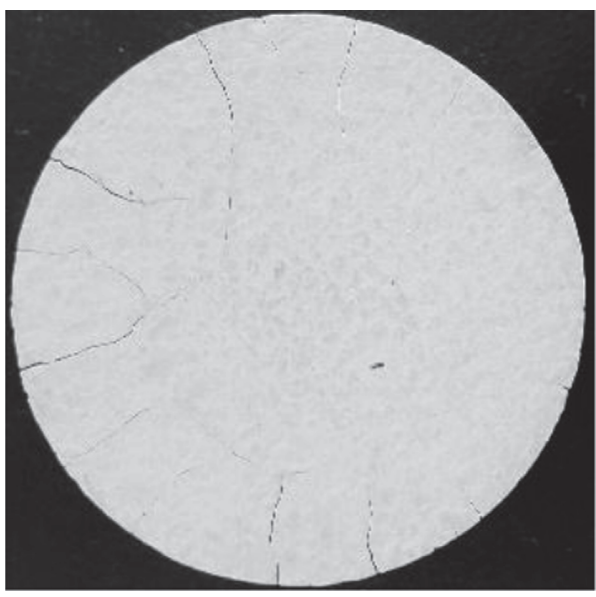

(c)

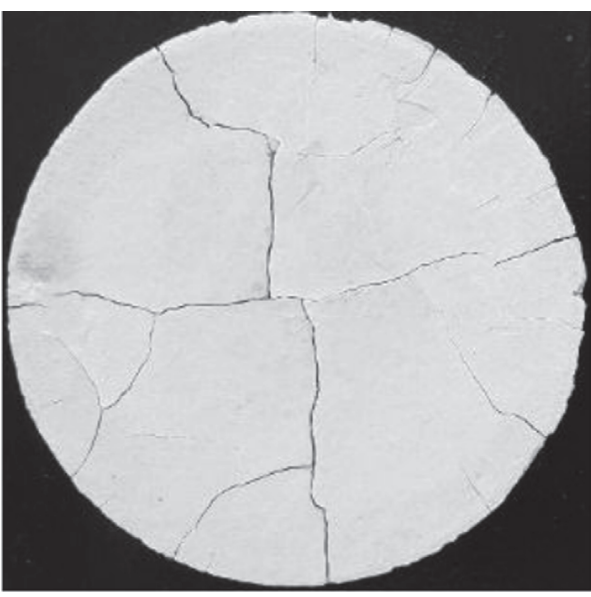

(b)

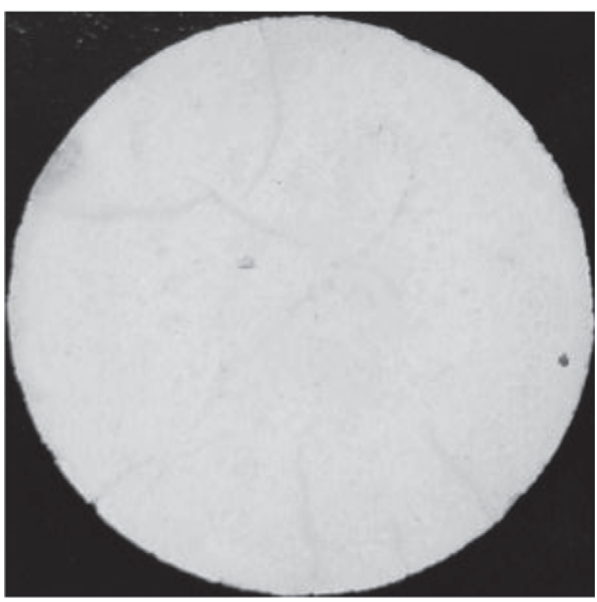

(d)

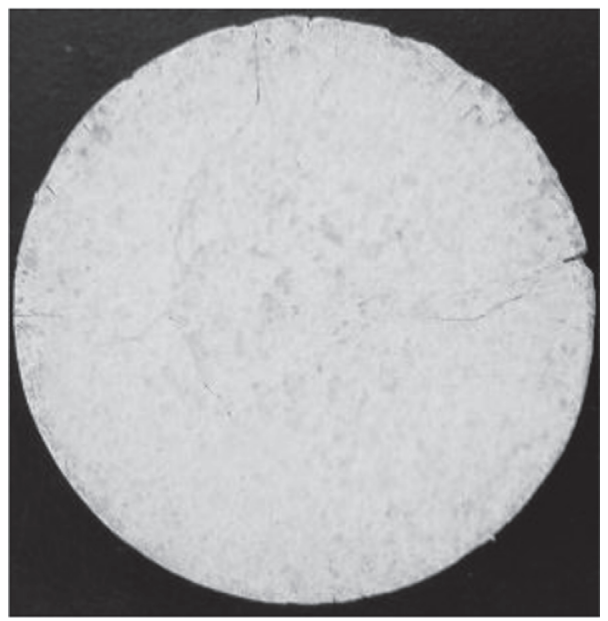

(e)

FIGURE 7: Images of specimens at the completion of the drying test: (a) DW, (b) $0.5 \mathrm{Na}-\mathrm{T}$, (c) $0.5 \mathrm{Ca}-\mathrm{T}$, (d) $2.0 \mathrm{Na}-\mathrm{T}$, and (e) $2.0 \mathrm{Ca}-\mathrm{T}$.

the salt concentration increases, the rate of crack growth (i.e., $-d_{\delta} / d_{w}$ value in the first stage) together with the peak and final surface crack ratio decreases. The saline solutions exert a remarkable inhibiting effect on desiccation cracking, and at a given concentration, the $\mathrm{CaCl}_{2}$ solution is more effective in restraining crack development.
3.4. Effect of Salt Solution on Volume Shrinkage. The direct use of the outer dimensions measured by caliper in the calculation of the soil volume will lead to an underestimate of the volumetric shrinkage of specimens as the calculated bulk volume incorporates the crack space. Given the difficulty associated with the accurate estimation of crack 


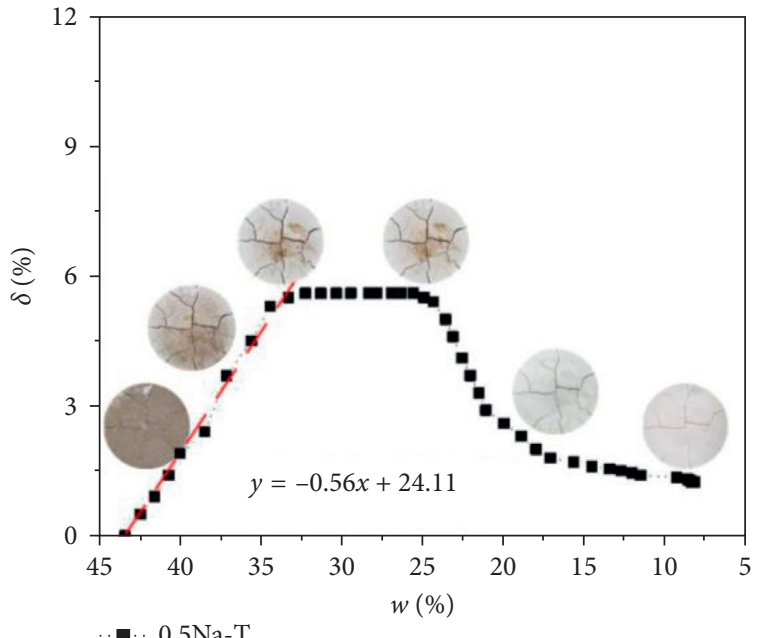

(a)

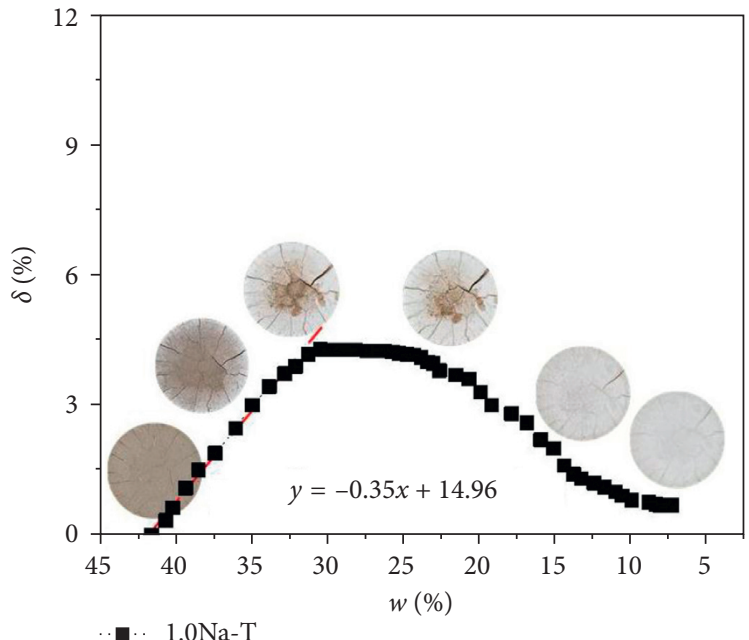

(b)

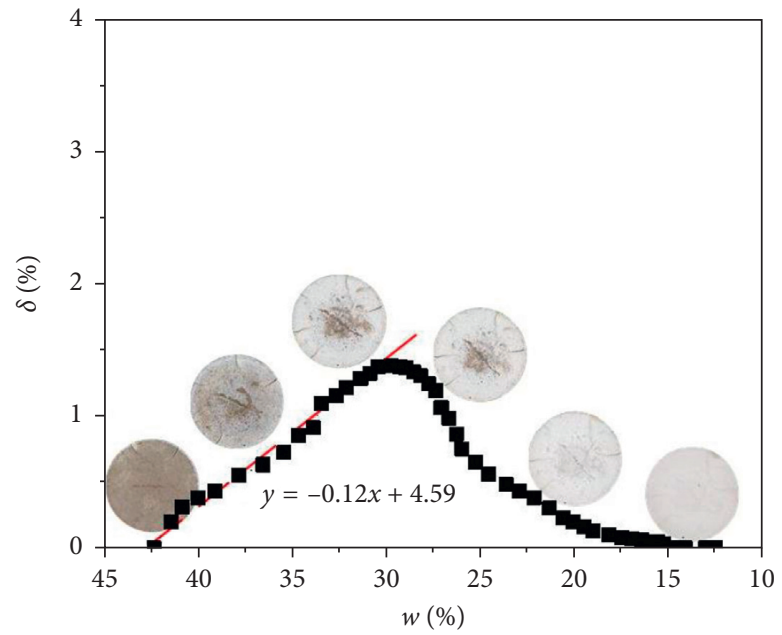

- . $2.0 \mathrm{Na}-\mathrm{T}$

(c)

FIGURE 8: Variation of surface crack ratio $(\delta)$ with water content $(\omega)$ for specimens saturated with $\mathrm{NaCl}$ solutions.

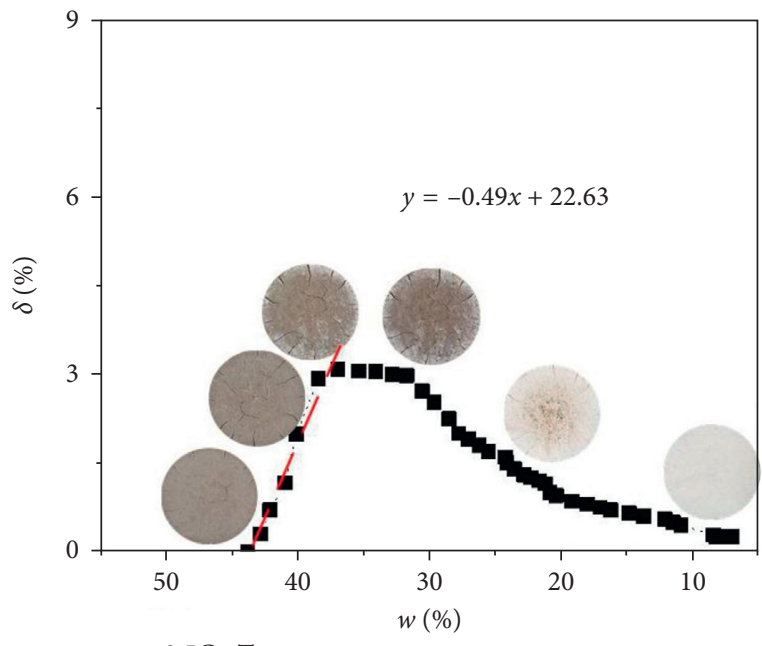

-. $0.5 \mathrm{Ca}-\mathrm{T}$

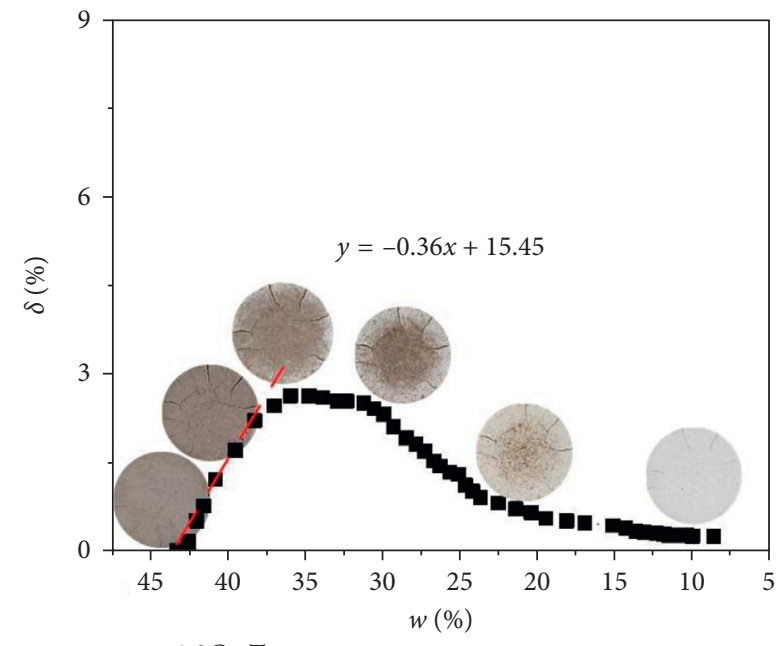

- $1.0 \mathrm{Ca}-\mathrm{T}$

(a)

Figure 9: Continued. 


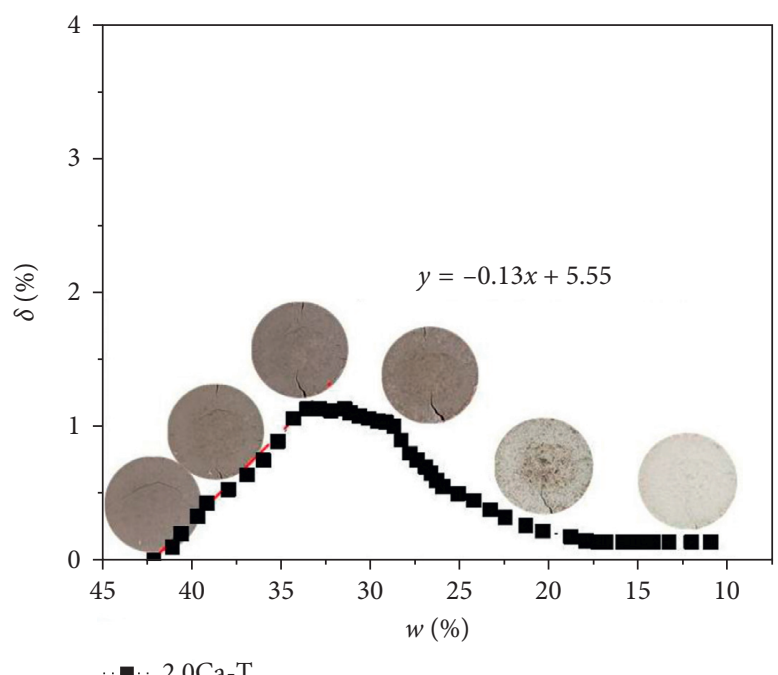

(c)

FIgURE 9: Variation of surface crack ratio $(\delta)$ with water content $(\omega)$ for specimens saturated with $\mathrm{CaCl}_{2}$ solutions.

TABLE 4: Associated parameters of the cracking for different specimens.

\begin{tabular}{lccc}
\hline Designation & $-d_{\delta} / d_{\omega}$ (crack growth stage) & Peak surface crack ratio (\%) & Final surface crack ratio (\%) \\
\hline DW & 0.84 & 8.75 & 3.51 \\
$0.5 \mathrm{Na}-\mathrm{T}$ & 0.56 & 5.6 & 1.24 \\
$1.0 \mathrm{Na}-\mathrm{T}$ & 0.36 & 4.29 & 0.68 \\
$2.0 \mathrm{Na}-\mathrm{T}$ & 0.12 & 1.38 & 0 \\
$0.5 \mathrm{Ca}-\mathrm{T}$ & 0.49 & 3.09 & 0.25 \\
$1.0 \mathrm{Ca}-\mathrm{T}$ & 0.36 & 2.62 & 0.22 \\
$2.0 \mathrm{Ca}-\mathrm{T}$ & 0.13 & 1.13 & 0.14 \\
\hline
\end{tabular}

volume upon soil drying due to the random variation of crack patterns, only the total shrinkage deformation of the specimens after the desiccation test is considered and analyzed. The total axial shrinkage strain $\varepsilon_{a}$, radial shrinkage strain $\varepsilon_{r}$, and volumetric shrinkage strain $\varepsilon_{v}$ were determined using the following equations:

$$
\begin{aligned}
\varepsilon_{\mathrm{a}} & =\frac{\left(h_{0}-h_{f}\right)}{h_{0}} ; \\
\varepsilon_{\mathrm{r}} & =\frac{\left(d_{0}-d_{f}^{\prime}\right)}{d_{0}} ; \\
\varepsilon_{\mathrm{v}} & =\frac{\left(V_{0}-V_{1}\right)}{V_{0}}, \\
V_{f} & =\pi\left(d_{f}\right)^{2} h_{f} \frac{\left(1-\delta\left(h_{c} / h_{f}\right)\right)}{4} \\
d_{f}^{\prime} & =\sqrt[2]{\frac{4 V_{f}}{\pi h_{f}}}
\end{aligned}
$$

where $d_{0}, h_{0}$, and $V_{0}$ are the initial diameter, height, and volume, respectively, of a specimen. $h_{f}$ and $d_{f}$ are the final diameter and height of the specimen measured with a vernier caliper, while $V_{f}$ is the actual volume of the specimen after the drying test (i.e., the bulk volume minus the volume of cracks). $h_{c}$ is the average depth of the cracks in the vertical direction of the specimen, and for cracks that extend from the top surface to the base of the specimen, such as the case of specimen DW illustrated in Figure $7(\mathrm{a}), h_{c} / h_{f}=1$. The equivalent diameter $d_{f}^{\prime}$, which has eliminated the effect of crack width, was estimated with equation (2).

The calculated results of shrinkage strain parameters are presented in Table 5, which indicate that the shrinkage strains of specimen DW are the largest in magnitude. The salinization of the specimen leads to noticeable reduction in shrinkage strain which appears to decrease with an increase in the solution concentration. In addition, all specimens showed anisotropy of shrinkage, which is reflected by the difference between the axial and radial shrinkage strain value $\left(\varepsilon_{a}-\varepsilon_{r}\right)$; however, the anisotropy of shrinkage seems to become less significant as the solution concentration increases. It is seen from Table 5 that the value of $\varepsilon_{a}-\varepsilon_{r i}$ for specimen $\mathrm{DW}$ is the largest whereas that for specimen $2.0 \mathrm{Ca}-\mathrm{T}$ is almost equal to zero, indicating an isotropic shrinkage behavior.

The effect of the saline solutions on the shrinkage behavior of the bentonite was closely related to the change in the microstructure of bentonite subjected to salinization. Musso et al. [41] found that salinization can enhance the dual-porosity 
TABLE 5: Shrinkage strain parameters of bentonite specimens saturated with different salt solutions.

\begin{tabular}{|c|c|c|c|c|c|c|c|}
\hline Parameter (\%) & DW & $0.5 \mathrm{Na}-\mathrm{T}$ & $1.0 \mathrm{Na}-\mathrm{T}$ & $2.0 \mathrm{Na}-\mathrm{T}$ & $0.5 \mathrm{Ca}-\mathrm{T}$ & $1.0 \mathrm{Ca}-\mathrm{T}$ & $2.0 \mathrm{Ca}-\mathrm{T}$ \\
\hline Volumetric strain $\varepsilon_{v}$ & 32.00 & 27.65 & 26.87 & 25.81 & 23.65 & 22.78 & 20.24 \\
\hline Radial strain $\varepsilon_{r}$ & 11.12 & 9.47 & 9.60 & 9.25 & 8.02 & 8.05 & 7.25 \\
\hline Axial strain $\varepsilon_{a}$ & 13.90 & 11.70 & 10.50 & 9.87 & 9.75 & 8.71 & 7.27 \\
\hline$\varepsilon_{a}-\varepsilon_{r}$ & 2.78 & 2.23 & 0.90 & 0.62 & 1.73 & 0.66 & 0.02 \\
\hline
\end{tabular}

structure (i.e., interaggregate and intra-aggregate pores) of compacted clay and that the number of aggregated particles increases with the salt concentration. Thyagaraj and Salini [42] showed that the $\mathrm{CaCl}_{2}$ solution can induce more significant particle aggregation than the $\mathrm{NaCl}$ solution. These previous findings are in general agreement with the SEM observations presented in Section 3.1. As illustrated in Figure 4(b), the dispersed clay stacks within the specimen DW are relatively well oriented, and these oriented particles tend to get close to each other along a preferred direction during the drying process, which is the main contribution to the anisotropy of shrinkage. In comparison, the salinized specimens have an aggregated structure in which the aggregations of clay particles are arranged in a more disordered manner; thus, the salinized specimens exhibited less evident shrinkage anisotropy, and specimen 2.0Ca- $\mathrm{T}$, with a more homogeneous distribution of aggregates, even shows isotropic shrinkage.

As mentioned above, the bentonite samples shrink less after being saturated by a salt solution. This may be attributed to two main reasons: (1) the clay mineral particles of the salinized specimens are bonded firmly together to form aggregates, and compared with the dispersed and relatively thin clay platelets or stacks in the specimen DW, the aggregated units possess a higher stiffness and hence exert more resistance against them moving closer together. Besides, the reorientation of particles during the drying process is conducive to making more room for the soil bulk shrinkage; however, the rearrangement of large aggregated units is very difficult and hence, this leads to limited void space to accommodate soil shrinkage. (2) For soils with an aggregate structure, such as salinized bentonite, desiccation will induce shrinkage of both the large interaggregate pores $\left(P_{M}\right)$ and intra-aggregate micropores $\left(P_{m}\right)$. The decrease in $P_{M}$ volume can be directly translated to the bulk volumetric shrinkage; however, the shrinkage of $P_{m}$, such as the reduction in the montmorillonite interlayer spacing, could be largely offset by an increase in the volume of mesopores within the aggregates and therefore be less effectively translated or upscaled to macroscopic shrinkage. For the same reasons, at a given solution concentration, the specimens treated with $\mathrm{CaCl}_{2}$, which have a more evident aggregate structure, generally show smaller shrinkage strains than those salinized by $\mathrm{NaCl}$, as indicated in Table 5 .

\section{Conclusions}

In this study, a series of desiccation tests was conducted on the compacted Gaomiaozi bentonite previously saturated with the salt solution to investigate the effects of salt type and concentration on the water evaporation, shrinkage deformation, and cracking behaviors of bentonite. Some observations are summarized as follows:

(1) The salinized bentonite specimens, compared with those saturated with deionized water, have relatively lower initial (saturated) water content but higher residual water content at the completion of the drying test. This results from salinization-induced osmotic suction and changes in the amount of strongly bound water. In the initial desiccation stage, the water evaporation rate is controlled by the combined influences from the soil structure and osmotic suction. The water evaporation rate decrease with an increase in the concentration of the saline solution, and $\mathrm{CaCl}_{2}$ leads to a more significant reduction in the soil water evaporation rate than $\mathrm{NaCl}$.

(2) The evolution of cracks during the drying process exhibited four stages: crack growth, maintenance, closure, and stabilization. Salinization inhibits the development of desiccation cracking of bentonite, with the surface crack ratio decreasing as the salt concentration increases. Besides, it is shown that, at a given concentration, the $\mathrm{CaCl}_{2}$ solution is more effective in inhibiting desiccation cracking than $\mathrm{NaCl}$.

(3) The infiltration of salt solutions causes the fabric of bentonite to change from a dispersed pattern to an aggregated one, which results in a reduction in shrinkage strain and shrinkage anisotropy of bentonite. The clay particle aggregation was found to become more significant as the saline solution concentration and cation valence increase, which is the main reason why less shrinkage occurred when bentonite was saturated with a high-concentration $\mathrm{CaCl}_{2}$ solution.

In sum, the experimental results indicate that the infiltration of a saline solution can lead to a decrease in the magnitude of volume shrinkage and cracking during the drying process, thus not impairing the hydraulic containment property of the buffer layer. Nevertheless, the osmotic suction and cation exchange induced by water salinity may, in turn, affect the swelling capacity and permeability of compacted bentonite subjected to rewetting. Therefore, it is necessary to investigate the simultaneous effects of saline solutions and wet-dry cycles on the swelling, shrinkage, and hydraulic conductivity of bentonite. Besides, the present work involves limited salt solution types and concentrations; further study employing saline solutions more comparable to real groundwater may be required to allow a more reasonable 
assessment of bentonite's desiccation behavior in the repository environment, thereby providing effective guidance for buffer/backfill design and safety.

\section{Data Availability}

The data used to support the findings of this study are available from the corresponding author upon reasonable request.

\section{Conflicts of Interest}

The authors declare that they have no conflicts of interest.

\section{Acknowledgments}

The authors would like to express their gratitude to the National Natural Science Foundation of China (NSFC) for providing financial support to this work (Grant no. 41972298).

\section{References}

[1] D. Dixon, T. Sanden, E. Jonsson, and J. Hansen, Backfilling of Deposition Tunnels: Use of Bentonite Pellets (No. SKB-P-1144), Swedish Nuclear Fuel and Waste Management Company, Stockholm, Sweden, 2011.

[2] Y. Guo, T. Yang, and S. Liu, "Hydrogeological characteristics of Beishan preselected area, Gansu province for China's highlevel radioactive waste repository," Uranium Geology, vol. 17, no. 3, pp. 184-189, 2001, (in Chinese).

[3] Y. Guo, S. Liu, T. Yang, and G. Jiang, "Isotope techniques for the research of groundwater in the potential site of China's high-level waste repository," Science in China Series E: Technological Sciences, vol. 44, no. 1, pp. 168-174, 2001.

[4] C.-M. Zhu, W.-M. Ye, Y.-G. Chen, B. Chen, and Y.-J. Cui, "Influence of salt solutions on the swelling pressure and hydraulic conductivity of compacted GMZ01 bentonite," Engineering Geology, vol. 166, pp. 74-80, 2013.

[5] S. Suzuki, M. Sazarashi, T. Akimoto, M. Haginuma, and K. Suzuki, "A study of the mineralogical alteration of bentonite in saline water," Applied Clay Science, vol. 41, no. 3-4, pp. 190-198, 2008.

[6] S. Kaufhold and R. Dohrmann, "Stability of bentonites in salt solutions | sodium chloride," Applied Clay Science, vol. 45, no. 3, pp. 171-177, 2009.

[7] D. Dixon, N. Chandler, J. Graham, and M. N. Gray, "Two large-scale sealing tests conducted at atomic energy of Canada's underground research laboratory: the buffer-container experiment and the isothermal test," Canadian Geotechnical Journal, vol. 39, no. 3, pp. 503-518, 2002.

[8] L. Boerjesson, D. Gunnarsson, L. E. Johannesson, and E. Jonsson, Design, Production and Initial State of the Backfill and Plug in Deposition Tunnels. (No. SKB-TR-10-16), Swedish Nuclear Fuel and Waste Management Company, Stockholm, Sweden, 2010.

[9] T. Sandén, L. Andersson, and V. Jensen, System Design of Backfill: Full Scale Production Test of Backfill Blocks. (No. SKBP-14-24), Swedish Nuclear Fuel and Waste Management Company, Stockholm, Sweden, 2015.

[10] S. J. Kowalski, Thermomechanics of Drying Processes, Springer Science \& Business Media, Berlin, Germany, 2012.
[11] C. S. Tang, B. Shi, C. Liu, W. B. Suo, and L. Gao, "Experimental characterization of shrinkage and desiccation cracking in thin clay layer," Applied Clay Science, vol. 52, no. 1-2, pp. 69-77, 2011a.

[12] C.-S. Tang, Y.-J. Cui, B. Shi, A.-M. Tang, and C. Liu, "Desiccation and cracking behaviour of clay layer from slurry state under wetting-drying cycles," Geoderma, vol. 166, no. 1, pp. 111-118, 2011.

[13] V. Y. Chertkov, I. Ravina, and V. Zadoenko, "An approach for estimating the shrinkage geometry factor at a moisture content," Soil Science Society of America Journal, vol. 68, no. 6, pp. 1807-1817, 2004.

[14] W. B. Haines, "The volume-changes associated with variations of water content in soil," The Journal of Agricultural Science, vol. 13, no. 3, pp. 296-310, 1923.

[15] G. Stirk, "Some aspects of soil shrinkage and the effect of cracking upon water entry into the soil," Australian Journal of Agricultural Research, vol. 5, no. 2, pp. 279-296, 1954.

[16] P. Boivin, P. Garnier, and D. Tessier, "Relationship between clay content, clay type, and shrinkage properties of soil samples," Soil Science Society of America Journal, vol. 68, no. 4, pp. 1145-1153, 2004.

[17] E. J. W. Verwey, "Theory of the stability of lyophobic colloids," The Journal of Physical and Colloid Chemistry, vol. 51, no. 3, pp. 631-636, 1947.

[18] T. A. Hueckel, "Water-mineral interaction in hygromechanics of clays exposed to environmental loads: a mixture-theory approach," Canadian Geotechnical Journal, vol. 29, no. 6, pp. 1071-1086, 1992.

[19] H. J. Butt, M. Farshchi-Tabrizi, and M. Kappl, "Using capillary forces to determine the geometry of nanocontacts," Journal of Applied Physics, vol. 100, no. 2, 2006.

[20] O. Karnland, Bentonite Swelling Pressure in Strong $\mathrm{NaCl}$ Solutions. Correlation between Model Calculations and Experimentally Determined Data (No. SKB-TR--97-31), Swedish Nuclear Fuel and Waste Management Company, Stockholm, Sweden, 1997.

[21] S. M. Rao and T. Thyagaraj, "Swell-compression behaviour of compacted clays under chemical gradients," Canadian Geotechnical Journal, vol. 44, no. 5, pp. 520-532, 2007.

[22] Y. Xu, G. Xiang, H. Jiang, T. Chen, and F. Chu, "Role of osmotic suction in volume change of clays in salt solution," Applied Clay Science, vol. 101, pp. 354-361, 2014.

[23] Y. He, Y. G. Chen, W. M. Ye, B. Chen, and Y. J. Cui, "Influence of salt concentration on volume shrinkage and water retention characteristics of compacted GMZ bentonite," Environmental Earth Sciences, vol. 75, no. 6, p. 535, 2016.

[24] X. D. Zhang, Y. G. Chen, W. M. Ye, Y. J. Cui, Y. F. Deng, and B. Chen, "Effect of salt concentration on desiccation cracking behavior of GMZ bentonite," Environmental Earth Sciences, vol. 76, no. 15, p. 531, 2017.

[25] ASTM, Standard Test Method for Swell Index of Clay Mineral Component of Geosynthetic Clay Liners, D 5890, American Society for Testing and Materials, Philadelphia, 2001.

[26] S. G. Garcia, M. Jonsson, and S. Wold, "Temperature effect on the stability of bentonite colloids in water," Journal of Colloid and Interface Science, vol. 298, no. 2, pp. 694-705, 2006.

[27] T. Guillon, R. Giot, A. Giraud, and G. Armand, "Response of Callovo-Oxfordian claystone during drying tests: unsaturated hydromechanical behavior," Acta Geotechnica, vol. 7, no. 4, pp. 313-332, 2012.

[28] P. Y. Hicher, H. Wahyudi, and D. Tessier, "Microstructural analysis of inherent and induced anisotropy in clay," 
Mechanics of Cohesive-Frictional Materials, vol. 5, no. 5, pp. 341-371, 2000.

[29] H. Sato and S. Suzuki, "Fundamental study on the effect of an orientation of clay particles on diffusion pathway in compacted bentonite," Applied Clay Science, vol. 23, no. 1-4, pp. 51-60, 2003.

[30] C. Di Maio, "Exposure of bentonite to salt solution: osmotic and mechanical effects," Géotechnique, vol. 46, no. 4, pp. 695-707, 1996.

[31] H. Zhang, Y. Tan, F. Zhu, D. He, and J. Zhu, "Shrinkage property of bentonite-sand mixtures as influenced by sand content and water salinity," Construction and Building Materials, vol. 224, pp. 78-88, 2019.

[32] Y. Zhang, W. Ye, Y. Chen, and B. Chen, "Impact of $\mathrm{NaCl}$ on drying shrinkage behavior of low-plasticity soil in earthen heritages," Canadian Geotechnical Journal, vol. 54, no. 12, pp. 1762-1774, 2017.

[33] P. F. Luckham and S. Rossi, "The colloidal and rheological properties of bentonite suspensions," Advances in Colloid and Interface Science, vol. 82, no. 1-3, pp. 43-92, 1999.

[34] S. M. Rao and T. Thyagaraj, "Role of direction of salt migration on the swelling behaviour of compacted clays," Applied Clay Science, vol. 38, no. 1-2, pp. 113-129, 2007.

[35] T. Thyagaraj, S. R. Thomas, and A. P. Das, "Physico-chemical effects on shrinkage behavior of compacted expansive clay," International Journal of Geomechanics, vol. 17, no. 2, 2017.

[36] N. An, C.-S. Tang, S.-K. Xu, X.-P. Gong, B. Shi, and H. I. Inyang, "Effects of soil characteristics on moisture evaporation," Engineering Geology, vol. 239, pp. 126-135, 2018.

[37] G. W. Wilson, D. G. Fredlund, and S. L. Barbour, "The effect of soil suction on evaporative fluxes from soil surfaces," Canadian Geotechnical Journal, vol. 34, no. 1, pp. 145-155, 1997.

[38] H. L. Bohn, R. A. Myer, and G. A. O'Connor, Soil Chemistry, John Wiley \& Sons, NJ, USA, 2002.

[39] J. N. Israelachvili, Intermolecular and Surface Forces, Academic Press, Cambridge, Massachusetts, 2011.

[40] P. Boivin, "Anisotropy, cracking, and shrinkage of vertisol samples experimental study and shrinkage modeling," Geoderma, vol. 138, no. 1-2, pp. 25-38, 2007.

[41] G. Musso, E. Romero, and G. Della Vecchia, "Doublestructure effects on the chemo-hydro-mechanical behaviour of a compacted active clay," in Proceedings of the Bio-and Chemo-Mechanical Processes in Geotechnical Engineering: Géotechnique Symposium in Print 2013, pp. 3-17, ICE Publishing, London, UK, 2014.

[42] T. Thyagaraj and U. Salini, "Effect of pore fluid osmotic suction on matric and total suctions of compacted clay," Géotechnique, vol. 65, no. 11, pp. 952-960, 2015. 